\title{
Effect of Donor Age on Outcome of Lung Transplantation Stratified by Recipient Diagnosis : A Nordic Multicenter Study
}

\section{Auraen, Henrik}

2019-04

Auraen, H, Durheim , M T , Dellgren, G, Hammainen, P, Larsson , H, Geiran , O , Schultz , H H L , Leuckfeld , I , Iversen , M , Fiane , A \& Holm , A M 2019 , ' Effect of Donor Age on Outcome of Lung Transplantation Stratified by Recipient Diagnosis : A Nordic Multicenter Study ' , Transplantation , vol. 103 , no. 4 , pp. 807-814 . https://doi.org/10.1097/TP.0000000000002402

http://hdl.handle.net/10138/324664

https://doi.org/10.1097/TP.0000000000002402

unspecified

publishedVersion

Downloaded from Helda, University of Helsinki institutional repository.

This is an electronic reprint of the original article.

This reprint may differ from the original in pagination and typographic detail.

Please cite the original version. 


\section{Effect of Donor Age on Outcome of Lung Transplantation Stratified by Recipient Diagnosis: A Nordic Multicenter Study}

Henrik Auråen, MD, ${ }^{1,2}$ Michael Thomas Durheim, MD, ${ }^{1}$ Göran Dellgren, MD, PhD, ${ }^{3}$ Pekka Hämmäinen, MD, PhD, ${ }^{4}$ Hillevi Larsson, MD, ${ }^{5}$ Odd Geiran, MD, PhD, ${ }^{2,6}$ Hans Henrik Lawaetz Schultz, MD, PhD, ${ }^{7}$ Inga Leuckfeld, MD, PhD, ${ }^{1}$ Martin Iversen, MD, PhD, ${ }^{7}$ Arnt Fiane, MD, PhD, ${ }^{2,6}$ and Are Martin Holm, MD, $\mathrm{PhD}^{1,2}$

Background. Organs from older donors are increasingly used in lung transplantation, and studies have demonstrated that this could be safe in selected recipients. However, which recipient groups that have the largest benefit of older organs are unclear. This multicenter study reviews all bilateral lung transplantations (BLTx) from donors 55 years or older stratified by recipient diagnosis and compares outcomes with transplantations from younger donors. Methods. All BLTx recipients (excluding retransplantation) at 5 Scandiatransplant centers between 2000 and 2013 were included $(n=913)$. Recipients were stratified to diagnosis groups including cystic fibrosis (CF), chronic obstructive pulmonary disease (COPD), interstitial lung disease (ILD), and "other." Intensive care unit (ICU) length of stay (LOS) and survival were assessed. Results. Overall, there was no difference in survival among patients transplanted from donors 55 years or older compared with younger donors. However, in CF recipients, donor age 55 years or older was associated with inferior survival $(P=0.014)$, and this remained significant in a multivariate model (hazard ratio, 5.0; 95\% confidence interval, $1.8-14.1 ; P=0.002$ ). There was no significant effect of donor age on survival in recipients with COPD, ILD, or in the "other" group in multivariate models. Utilization of older donors was associated with increased ICU LOS for recipients with CF and ILD, but not in the COPD or "other" group. Conclusions. The BLTx recipients with CF had inferior survival and longer ICU LOS when receiving organs from donors 55 years or older. Recipients with COPD, ILD, or in the "other" group did not have inferior survival in multivariate models.

(Transplantation 2019;103: 807-814

O ne of the principal challenges in lung transplantation (LTx) is the scarcity of available donor organs. ${ }^{1} \mathrm{~A}$ way to overcome this challenge is to accept organs from older donors. According to the traditional ideal lung donor criteria, lung donors should be younger than 55 years. ${ }^{2}$ Still, most transplant centers use donors well above this limit as several studies have indicated that organs from older donors may be used without adverse consequences in lung recipients. ${ }^{3-5}$

Received 5 April 2018. Revision received 7 July 2018.

Accepted 1 August 2018.

'Department of Respiratory Medicine, Oslo University Hospital, Rikshospitalet, Norway.

${ }^{2}$ Faculty of Medicine, University of Oslo, Norway.

${ }^{3}$ Department of Cardiothoracic Surgery and Transplant Institute, Sahlgrenska University Hospital, Gothenburg, Sweden.

${ }^{4}$ Department of Cardiothoracic Surgery, Helsinki University Hospital, Finland.

${ }^{5}$ Division of Respiratory Medicine and Allergology, Department of Clinical Sciences, Lund University, Skåne University Hospital, Lund, Sweden.

${ }^{6}$ Department of Cardiothoracic Surgery, Oslo University Hospital Rikshospitalet, Norway.

Division of Lung Transplantation, Department of Cardiology, Copenhagen University Hospital, Rigshospitalet, Denmark.

A.H. received funding from The Norwegian Respiratory Society to conduct this research.
However, some studies that investigate the impact of using older lung donors are limited by heterogeneous study populations, including both single LTxs (SLTx) and bilateral LTxs (BLTx) and also primary transplantations and retransplantations (ReTx). Also, only very few studies have investigated the effect of donor age stratified by recipient diagnosis group. Furthermore, the observations reported may often be influenced by a selection bias, as

The authors declare no conflicts of interest.

A.H. participated in the research design, writing, performance of research, data analysis. D.M.T. participated in the research design, writing, performance of research, and data analysis. D.G. participated in the writing and performance of the research. H.P. participated in the writing and performance of the research. L.H. participated in the writing and performance of the research. G.O. participated in the writing and performance of the research. L.S.H.H. participated in the writing and performance of research. L.I. participated in the writing and performance of the research. I.M. participated in the writing and performance of the research. F.A.E. participated in the writing and performance of the research. H.A.M. participated in the research design, writing, performance of research, and data analysis.

Correspondence: Henrik Auråen, MD, Department of Respiratory Medicine, Oslo University Hospital, Rikshospitalet, Norway. (henrikauraen@gmail.com).

Copyright (C) 2018 Wolters Kluwer Health, Inc. All rights reserved.

ISSN: 0041-1337/19/10304-0807

DOI: $10.1097 /$ TP.0000000000002402 
lungs from older donors are often avoided in younger recipients. For instance, several studies include none or few recipients with cystic fibrosis (CF) who have received lungs from older donors. ${ }^{6,7}$ Thus, it is unclear whether such findings can be generalized to all lung recipients, and the question of which lung recipients are best suited for such organs needs further clarification.

Recently, there have been some studies addressing this question. One study including 23704 LTx recipients showed that younger recipients receiving lungs from older donors had inferior survival. ${ }^{6}$ Also, it has been shown that organs from older donors yield inferior survival in recipients with pulmonary hypertension and prolonged cardiac bypass time. ${ }^{7}$ These important findings indicate that older donors are acceptable in some recipient groups, but may be less suitable in others.

This multicenter study aims to assess the consequence of using organs from donors older than recommended by the ideal donor criteria ( $\geq 55 \mathrm{y}$ ) in BLTx for different recipient diagnoses. As patients with different forms of end-stage lung disease differ in terms of age, comorbidity, respiratory tract microbiome, and other factors, it is possible that donor age is relevant for some groups and irrelevant for others. If differences between groups are identified, allocation may be optimized to ensure maximum overall recipient survival.

\section{MATERIALS AND METHODS}

\section{Study Design}

All patients undergoing LT $\mathrm{x}$ from traditional heart-beating donors in Denmark (Copenhagen), Finland (Helsinki), Norway (Oslo), and Sweden (Gothenburg and Lund) in the period 2000 to 2013 were included in the study. To minimize confounding of survival, ReTx, multiorgan transplantations, and SLTx were excluded. Recipients were stratified to the following diagnosis groups: CF, chronic obstructive pulmonary disease (COPD), interstitial lung disease (ILD), and "other." Patients with lymphangioleiomyomatosis (LAM) were stratified to the "other" group as these patients were considered clinically different from other types of ILD. The primary end-point of the study was recipient posttransplant survival. In addition, short-term complications were assessed by intensive care unit (ICU) length of stay (LOS) after transplantation.

\section{Donor and Recipient Data}

Donor and recipient characteristics were collected from the Scandiatransplant Registry and local registries. Donor parameters included age, sex, body mass index (BMI), cause of death, last arterial partial pressure of oxygen $\left(\mathrm{PaO}_{2}\right)$ divided by fraction of inspired oxygen $\left(\mathrm{FiO}_{2}\right)$, and predicted total lung capacity (pTLC) calculated by donor height, sex, age, ${ }^{8}$ and donor smoking status. Donor smoking status was dichotomized to any history of regular smoking versus no history of regular smoking. Recipient parameters included age, gender, and BMI. Furthermore, percent of predicted forced expiratory volume in $1 \mathrm{sec}-$ ond $\left(\mathrm{FEV}_{1} \%\right)$ and 6-minute walk test $(6 \mathrm{MWT})$ at last follow-up were assessed. Also, the use of extracorporeal membrane oxygenation (ECMO) or mechanical ventilation (MV) as bridge to LTx and urgent listing status was considered. Urgent listing was introduced in the Scandiatransplant countries in 2009 and gives recipient considered as urgent priority when an organ becomes available in the Scandiatransplant region. ${ }^{9}$

\section{Statistical Analysis}

Normally distributed continuous data were presented as mean and standard deviation (SD) and compared using Student $t$ test. Continuous data with other distributions were presented as median and interquartile range (IQR) and compared using the nonparametric Mann-Whitney $U$ test. Spearman correlations were used to assess correlation between continuous variables. Categorical variables were presented as counts and percentages, and compared using Fisher exact test.

Certain variables had missing data that appeared randomly distributed among the subjects. Primarily, this was evident for donor smoking status where $37.7 \%$ of the data were unavailable. Subjects with missing data were excluded from multivariate models.

Recipient survival was initially assessed using KaplanMeier plots and the log rank test. To estimate the direct effect of using donors above the recommended age criteria $(\geq 55 \mathrm{y})$, a directed acyclic $\operatorname{graph}^{10}$ was used to build a multivariate Cox-regression model with relevant covariates. The relevant covariates were found to be recipient age, recipient urgency, cold ischemia time, donor smoking status, and donor cause of death. Recipient life support (ECMO or MV) and/or Scandiatransplant urgent listing and recipient $\mathrm{BMI}$ were used as surrogates for recipient urgency. A previous multicenter study has shown that cold ischemia time has a cubic relationship with recipient survival, and that 330 minutes is a meaningful cutoff value. ${ }^{11}$ Cold ischemia time was therefore recoded as a dichotomous variable using this cutoff value. As $37.7 \%$ of donor smoking data were unavailable, models were built with and without this variable. The Cox proportional hazard assumption was assessed using Schoenfeld residuals. For all analyses, $P$ values less than 0.05 were considered statistically significant.

STATA version 15 for Mac (StataCorp LP, College Station, TX) was used for all statistical analyses and GraphPad Prism version 6 (GraphPad Software Inc., La Jolla, CA) was used for all graphs except Figure 1.

\section{Ethical Considerations}

The study used anonymized data from registries authorized by the regional ethics committees for the respective transplant centers.

\section{RESULTS}

In total, 1489 patients underwent primary LTx in the period 2000 to 2013 at the 5 Scandiatransplant centers that perform lung transplantations. SLTx $(n=475), \operatorname{ReTx}$ $(\mathrm{n}=50)$, multiorgan transplantations $(\mathrm{n}=44)$, and patients with completely missing data sets $(\mathrm{n}=7)$ were excluded. The patients that were retransplanted had a median age of 44 years (IQR, 29-52) and $11(22 \%)$ received organs from donors $\geq 55$ y. Furthermore, $14(28 \%)$ had CF (1 organ from donors $\geq 55 \mathrm{y}), 8(16 \%)$ had COPD ( 3 organs from donors $\geq 55 \mathrm{y}), 15(30 \%)$ had ILD (4 organs from donors $\geq 55 \mathrm{y}$ ), and $13(26 \%$ ) had other diagnoses ( 2 organs from 


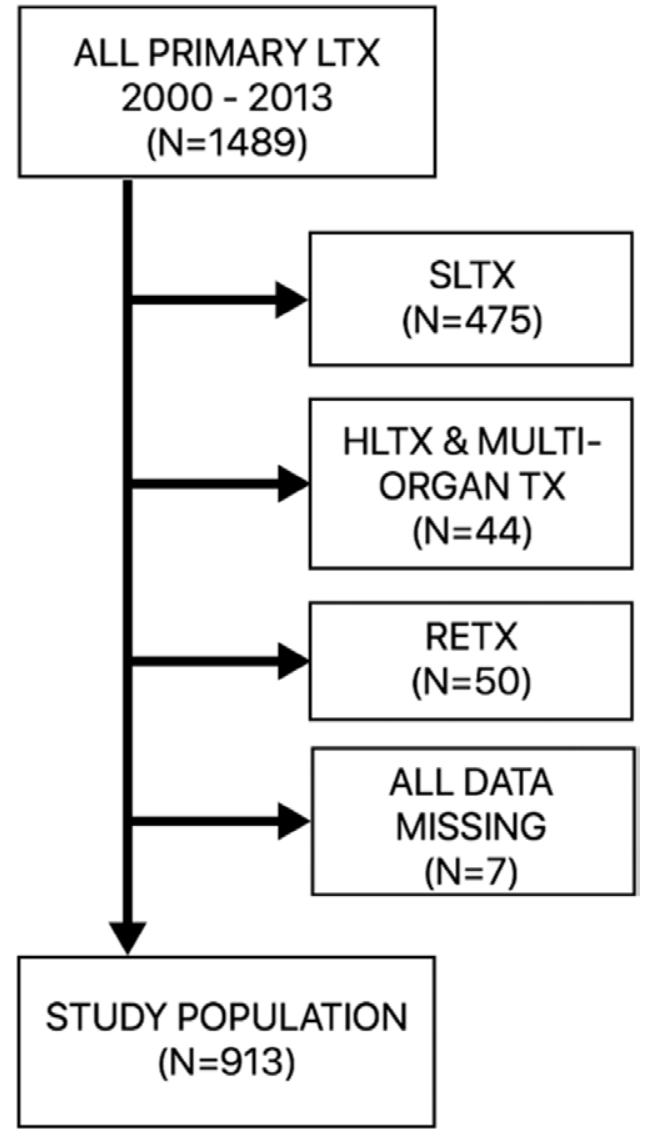

FIGURE 1. Flowchart illustrating the exclusions in this study. HLTx, heart-lung transplantation; LTx, lung transplantation; ReTx, retransplantation; SLTX, single lung transplantation.

donors $\geq 55$ years). Thus, as stated above, to minimize confounding factors, the ReTx patients were excluded from further analyses. In total, 913 BLTx recipients remained in the study population (Figure 1).

\section{Donor Characteristics}

Median donor age in the older donor group (donors, $\geq 55 \mathrm{y}$ ) was 60 years (IQR, 57-64) and 41 years (IQR, 26-48) in the younger donor group. Donor age distributions stratified by recipient diagnosis are shown in Figure 2. Further donor characteristics stratified by recipient diagnosis and donor age group are summarized in Table 1. Notably, the utilization of older donor lungs was significantly different between the recipient diagnosis groups (CF, 19\%; COPD, $32 \%$; ILD, $30 \%$; "other," $25 \%$; $P=0.009)$. In recipients with CF, COPD, and ILD older donors had a higher BMI. Furthermore, in recipients with COPD and ILD, older donors were more commonly females. Stroke was more common as cause of death for older donors in all diagnosis groups. In recipients with ILD, older donors had lower pTLC. Notably, there were no significant differences in cigarette smoking history or donor oxygenation between the 2 donor age groups.

\section{Recipient Characteristics}

Recipient characteristics stratified by recipient diagnosis and donor age group are summarized in Table 2. In total, $18.1 \%$ of the recipients had CF, $40.4 \%$ had COPD, $25.4 \%$ had ILD, and $16.1 \%$ had other diagnoses. The largest diagnosis groups in the "other" group were primary pulmonary arterial hypertension $(31.3 \%)$, non-CF bronchiectasis $(16.3 \%)$, LAM $(9.5 \%)$, and graft-versus-host disease after bone marrow transplantation $(5.4 \%)$. Notably, recipients with COPD, ILD, or in the "other" group receiving organs from donors 55 years or older were significantly older than recipients receiving younger organs, whereas no such difference was seen in recipients with CF. Moreover, in recipients with $\mathrm{CF}$ and $\mathrm{COPD}$, those receiving organs from older donors had higher BMI than those who received organs from younger donors. Patients with COPD receiving older organs had lower 6MWT compared with those receiving younger organs. For all other recipients, however, there were no significant differences in $6 \mathrm{MWT}$ or $\mathrm{FEV}_{1} \%$ between the 2 donor age groups. Notably, patients with CF and ILD receiving older organs were more commonly on ECMO or MV intended as bridge to transplantation compared with those receiving younger organs. The CF patients receiving older organs were also more commonly listed as urgent in the Scandiatransplant international organ exchange system.

\section{Recipient and Donor Age Matching}

For the overall population, recipient and donor age were significantly correlated $(\rho=0.276 ; P<0.001)$. This was also evident in the $\operatorname{COPD}(\rho=0.188 ; P<0.001)$, ILD $(\rho=0.238 ; P<0.001)$, and other diagnoses $(\rho=0.390$; $P<0.001)$ subgroups. However, there was no significant correlation between donor and recipient age in the CF subgroup $(\rho=0.059 ; P=0.451)$.

Donor Age Recipient Age

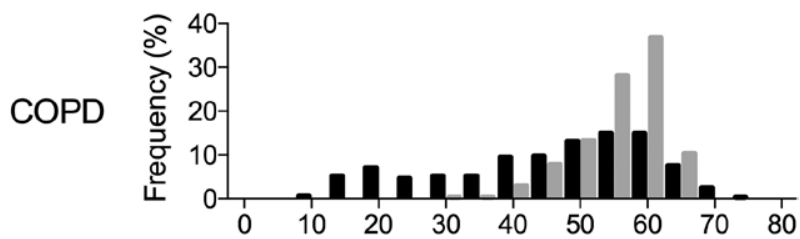

ILD

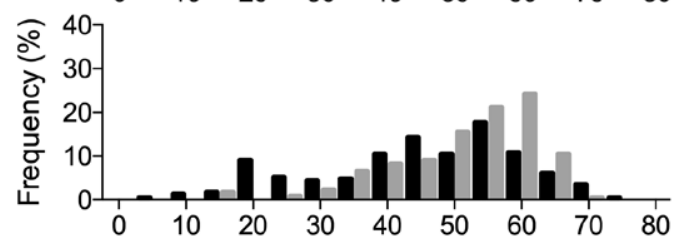

CF
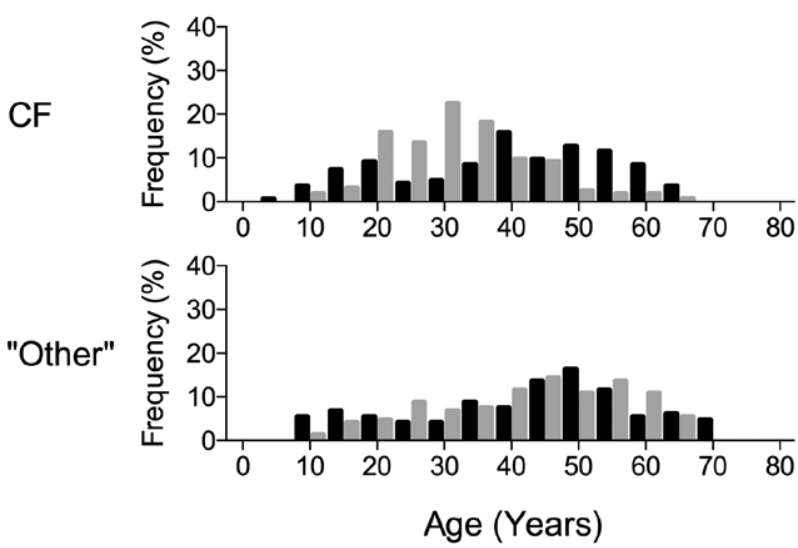

FIGURE 2. Donor and recipient age distributions for the diagnosis groups. CF, cyctic fibrosis; COPD, chronic obstructive pulmonary disease; ILD, interstitial lung disease. 
TABLE 1.

\section{Donor characteristics}

\begin{tabular}{|c|c|c|c|}
\hline \multirow[b]{2}{*}{$\begin{array}{l}\text { Variables }^{a} \\
\text { CF }\end{array}$} & \multicolumn{2}{|c|}{ Donor age } & \multirow[b]{2}{*}{$P$} \\
\hline & $<55$ y & $\geq 55 y$ & \\
\hline $\mathrm{n}$ & 134 & 31 & \\
\hline Age, y & $38(21-47)$ & $59(57-61)$ & $<0.001^{*}$ \\
\hline Males & $43.3 \%$ & $35.5 \%$ & 0.545 \\
\hline $\mathrm{BMI}, \mathrm{kg} / \mathrm{m}^{2}$ & $22.9(21.2-25.7)$ & $24.6(23.1-26.4)$ & $0.013^{*}$ \\
\hline $\mathrm{P}_{\mathrm{a}_{2}} \mathrm{~F}_{2} / \mathrm{Fi}_{2}$ ratio, $\mathrm{kPa}$ & $47.9(17.7)$ & $42.5(12.1)$ & 0.189 \\
\hline $\mathrm{pTLC}^{\mathrm{a}} \mathrm{C}, \mathrm{L}^{2}$ & $5.7(5.1-6.9)$ & $5.3(4.8-6.9)$ & 0.197 \\
\hline $\begin{array}{l}\text { History of regular } \\
\text { cigarette smoking }\end{array}$ & & & 0.431 \\
\hline Yes & $23.1 \%$ & $16.1 \%$ & \\
\hline Unknown & $26.1 \%$ & $19.3 \%$ & \\
\hline Cause of death & & & $0.034^{*}$ \\
\hline Stroke & $63.4 \%$ & $83.9 \%$ & \\
\hline Other & $36.6 \%$ & $16.1 \%$ & \\
\hline $\begin{array}{l}\text { Ischemia time, } \mathrm{h} \\
\text { COPD }\end{array}$ & $6.0(2.3)$ & $5.3(2.0)$ & 0.230 \\
\hline $\mathrm{n}$ & 250 & 119 & \\
\hline Age, y & $42(27-49)$ & $61(58-64)$ & $<0.001^{\star}$ \\
\hline Males & $56.6 \%$ & $42.9 \%$ & $0.014^{*}$ \\
\hline $\mathrm{BMl}, \mathrm{kg} / \mathrm{m}^{2}$ & 23.9 (21.6-25.7) & 24.5 (23.1-26.2) & $0.002^{*}$ \\
\hline $\mathrm{P}_{2} \mathrm{O}_{2} / \mathrm{F}_{1} \mathrm{O}_{2}$ ratio, $\mathrm{kPa}$ & $48.4(18.2)$ & $46.2(19.9)$ & 0.389 \\
\hline pTLC, L & 6.7 (5.2-7.4) & 5.5 (5.1-7.3) & 0.117 \\
\hline $\begin{array}{l}\text { History of regular } \\
\text { cigarette smoking }\end{array}$ & & & 0.581 \\
\hline Yes & $24.8 \%$ & $29.4 \%$ & \\
\hline Unknown & $39.6 \%$ & $39.4 \%$ & \\
\hline Cause of death & & & $<0.001^{\star}$ \\
\hline Stroke & $59.6 \%$ & $89.1 \%$ & \\
\hline Other & $40.4 \%$ & $10.9 \%$ & \\
\hline $\begin{array}{l}\text { Ischemia time, } \mathrm{h} \\
\text { ILD }\end{array}$ & $4.2(1.6)$ & $4.6(2.2)$ & 0.064 \\
\hline $\mathrm{n}$ & 163 & 69 & \\
\hline Age, y & $42(27-49)$ & $60(57-64)$ & $<0.001^{\star}$ \\
\hline Males & $44.8 \%$ & $29.0 \%$ & $0.028^{*}$ \\
\hline BMI, $\mathrm{kg} / \mathrm{m}^{2}$ & $23.9(21.6-25.9)$ & 24.7 (23.1-26.1) & $0.026^{*}$ \\
\hline $\mathrm{P}_{\mathrm{a}} \mathrm{O}_{2} / \mathrm{FiO}_{2}$ ratio, $\mathrm{kPa}$ & $47.6(19.5)$ & $44.3(18.3)$ & 0.385 \\
\hline pTLC & $5.6(5.1-7.3)$ & $5.2(5.1-6.5)$ & $0.009^{*}$ \\
\hline $\begin{array}{l}\text { History of regular } \\
\text { cigarette smoking }\end{array}$ & & & 0.101 \\
\hline Yes & $25.9 \%$ & $20.2 \%$ & \\
\hline Unknown & $36.8 \%$ & $52.1 \%$ & \\
\hline Cause of death & & & $<0.001^{\star}$ \\
\hline Stroke & $60.7 \%$ & $88.4 \%$ & \\
\hline Other & $39.3 \%$ & $11.6 \%$ & \\
\hline $\begin{array}{l}\text { Ischemia time } \\
\text { "Other" }\end{array}$ & $4.9(1.9)$ & $5.6(3.0)$ & 0.092 \\
\hline $\mathrm{n}$ & 110 & 37 & \\
\hline Age, y & $40(24-48)$ & $60(57-66)$ & $<0.001^{*}$ \\
\hline Males & $41.8 \%$ & $37.8 \%$ & 0.703 \\
\hline $\mathrm{BMI}, \mathrm{kg} / \mathrm{m}^{2}$ & $23.4(20.8-26.0)$ & 23.5 (22.0-25.5) & 0.313 \\
\hline $\mathrm{P}_{\mathrm{a}} \mathrm{O}_{2} / \mathrm{FiO}_{2}$ ratio, $\mathrm{kPa}$ & $50.3(26.7)$ & $49.6(11.5)$ & 0.898 \\
\hline pTLC, L & $5.4(5.1-7.1)$ & $5.3(5.1-6.9)$ & 0.588 \\
\hline
\end{tabular}

Continued
TABLE 1. (Continued)

\begin{tabular}{lccc}
\hline \multicolumn{3}{c}{ Donor age } \\
\hline $\begin{array}{l}\text { History of regular } \\
\text { cigarette smoking }\end{array}$ & & & 0.622 \\
$\quad$ Yes & $15.5 \%$ & $16.2 \%$ & \\
$\quad$ Unknown & $40 \%$ & $48.6 \%$ & \\
Cause of death & & & $0.047^{*}$ \\
$\quad$ Stroke & $59.1 \%$ & $78.4 \%$ & \\
$\quad$ Other & $40.9 \%$ & $21.6 \%$ & \\
Ischemia time, h & $5.0(1.9)$ & $5.1(2.0)$ & 0.848 \\
\hline
\end{tabular}

${ }^{a}$ Continuous variables presented as mean (standard deviation) or median (interquartile range) Dichotomous variables presented as percentage.

$\mathrm{BMI}$, body mass index; COPD, chronic obstructive pulmonary disease, FiO2, fraction of inspired oxygen; ILD, interstitial lung disease; Pa02, partial pressure of oxygen; pTLC, predicted total lung capacity.

\section{ICU LOS}

Median initial ICU LOS after LTx was 3 days (IQR, 2-7.5) and ranged 0 to 97 days. Furthermore, ICU LOS was significantly higher in recipients receiving donor lungs aged 55 years or older (median, 4 vs 3 ; IQR, $2-10$ vs $2-7$; $P=0.018)$ and also correlated significantly if donor age was analyzed as a continuous variable $(\rho=0.069 ; P=0.047)$. In contrast, there was no difference in ICU LOS for recipients aged 55 years or older compared with younger recipients (median, 3.5 vs 3 ; IQR, $2-7$ vs $2-8$; $P=0.835$ ), and no significant correlation between ICU LOS and recipient age as a continuous variable $(\rho=-0.009 ; P=0.802)$.

In recipients with $\mathrm{CF}$, the utilization of donors 55 years or older was associated with longer ICU LOS (Table 2). Notably, the ICU LOS was not significantly correlated with recipient age $(\rho=0.057 ; P=0.480)$. Also, in recipients with ILD the utilization of donors $\geq 55$ years was associated with longer ICU LOS (Table 2), and although the correlation coefficient for recipient age and ICU LOS was higher than in the CF group, it did not reach significance $(\rho=0.128$; $P=0.061)$. There were no significant differences in ICU LOS between recipients receiving organs $\geq 55$ years and younger organs for the COPD or the "other" subgroups (Table 2).

\section{Survival}

In the overall study population, 90-day, 1-year, and 5 -year survival were $94.7 \%, 86.5 \%$, and $67.6 \%$, respectively. There were no significant differences in 90 -day survival $(P=0.139), 1$-year survival $(P=0.451)$, or overall survival $(P=0.278)$ when comparing the utilization of donors 55 years or older with younger donors (Figure 3 ). In multivariate models (as described in methods), the utilization of donors 55 years or older was not associated with survival when donor smoking was excluded (hazard ratio $[\mathrm{HR}], 1.0 ; 95 \%$ confidence interval $[\mathrm{CI}] 0.8-1.4$; $P=0.851$ ) or included (HR, $1.0 ; 95 \% \mathrm{CI}, 0.7-1.4 ; P=0.981$ ).

Recipients with CF receiving organs from donors $\geq 55$ years did not have significant inferior 90-day survival but had inferior 1 -year, and overall survival $(P=0.014)$ compared to those receiving organs from younger donors (Table 2 and Figure 4). When adjusting for other covariates (both when excluding and including smoking), donors aged 55 years or older remained significantly negatively associated with survival (Table 3 ). 
TABLE 2.

Recipient characteristics

\begin{tabular}{|c|c|c|c|}
\hline & Dono & & \\
\hline $\begin{array}{l}\text { Variables }^{a} \\
\mathrm{CF}\end{array}$ & $<55 y$ & $\geq 55 y$ & $P$ \\
\hline n & 134 & 31 & \\
\hline Age, y & $30(24-37)$ & 33 (23-43) & 0.123 \\
\hline Males & $48.5 \%$ & $45.2 \%$ & 0.843 \\
\hline $\mathrm{BMI}, \mathrm{kg} / \mathrm{m}^{2}$ & $17.9(16.5-19.7)$ & $19.0(17.1-21.5)$ & $0.046^{\star}$ \\
\hline $\mathrm{FEV}_{1}, \%$ of predicted & 25 (21-32) & $23(20-30)$ & 0.466 \\
\hline 6MWT, m & 442 (338-519) & $435(331-520)$ & 0.549 \\
\hline ECMO/MV bridge & $8.1 \%$ & $31 \%$ & $0.003^{*}$ \\
\hline Listed as urgent $^{b}$ & $5.2 \%$ & $26 \%$ & $0.006^{*}$ \\
\hline ICU stay, d & $3(2-6)$ & $5(3-19)$ & $0.034^{*}$ \\
\hline 90-d survival & $96.2 \%$ & $87.1 \%$ & 0.065 \\
\hline $\begin{array}{l}\text { 1-y survival } \\
\text { COPD }\end{array}$ & $91.0 \%$ & $71.0 \%$ & $0.006^{\star}$ \\
\hline $\mathrm{n}$ & 250 & 119 & \\
\hline Age, y & $56(51-60)$ & 58 (54-61) & $0.007^{*}$ \\
\hline Males & $48.0 \%$ & $45.4 \%$ & 0.657 \\
\hline $\mathrm{BMl}, \mathrm{kg} / \mathrm{m}^{2}$ & $21.1(19.0-23.5)$ & $22.1(19.6-25.1)$ & $0.009^{\star}$ \\
\hline $\mathrm{FEV}_{1}, \%$ of predicted & 20 (17-25) & 22 (18-28) & 0.063 \\
\hline 6MWT, m & 270 (195-330) & 240 (152-315) & $0.022^{*}$ \\
\hline ECMO/MV bridge & $2.8 \%$ & $5.9 \%$ & 0.156 \\
\hline Listed as urgent $^{a}$ & $0.4 \%$ & $0.8 \%$ & 0.542 \\
\hline ICU stay, d & $3(2-5)$ & $3(2-5)$ & 0.102 \\
\hline 90-d survival & $96.0 \%$ & $96.6 \%$ & 0.999 \\
\hline $\begin{array}{l}\text { 1-y survival } \\
\text { ILD }\end{array}$ & $86.0 \%$ & $89.9 \%$ & 0.321 \\
\hline $\mathrm{n}$ & 163 & 69 & \\
\hline Age, y & $53(45-59)$ & $56(50-61)$ & $0.024^{\star}$ \\
\hline Males & $69.3 \%$ & $62.3 \%$ & 0.359 \\
\hline BMI, $\mathrm{kg} / \mathrm{m}^{2}$ & $24.7(22.1-27.8)$ & $25.3(22.0-29.0)$ & 0.346 \\
\hline $\mathrm{FEV}_{1}, \%$ of predicted & 43 (34-58) & 50 (40-58) & 0.152 \\
\hline 6MWT, m & 308 (165-431) & 305 (130-420) & 0.986 \\
\hline ECMO/MV bridge & $6.9 \%$ & $24.6 \%$ & $0.001^{*}$ \\
\hline Listed as urgent $^{a}$ & $7.9 \%$ & $13.0 \%$ & 0.230 \\
\hline ICU stay, d & $5(2-10)$ & $6.5(3-26.5)$ & $0.018^{*}$ \\
\hline 90-d survival & $96.9 \%$ & $88.4 \%$ & $0.023^{*}$ \\
\hline $\begin{array}{l}\text { 1-y survival } \\
\text { "Other" }\end{array}$ & $89.0 \%$ & $78.3 \%$ & $0.040^{*}$ \\
\hline$n$ & 110 & 37 & \\
\hline Age, y & $42(29-52)$ & $52(42-59)$ & $0.001^{*}$ \\
\hline Males & $31.8 \%$ & $29.7 \%$ & 0.999 \\
\hline $\mathrm{BMl}, \mathrm{kg} / \mathrm{m}^{2}$ & $21.3(19.4-24.6)$ & $21.4(20.2-25.4)$ & 0.243 \\
\hline $\mathrm{FEV}_{1}, \%$ of predicted & 30 (19-68) & 59 (22-76) & 0.057 \\
\hline 6MWT, m & $282(184-375)$ & 315 (220-364) & 0.552 \\
\hline ECMO/MV bridge & $10 \%$ & $13.9 \%$ & 0.554 \\
\hline Listed as urgent $^{b}$ & $6.3 \%$ & $5.4 \%$ & 0.999 \\
\hline ICU stay, d & $5(3-17)$ & $4.5(3-20)$ & 0.806 \\
\hline 90-d survival & $90.9 \%$ & $94.6 \%$ & 0.731 \\
\hline 1-y survival & $81.8 \%$ & $94.6 \%$ & 0.066 \\
\hline
\end{tabular}

${ }^{a}$ Continuous variables presented as median (interquartile range). Dichotomous variables presented as percentage.

${ }^{b}$ Listed as urgent in Scandiatransplant international organ exchange (from May 1, 2009). 6MWT, 6-minute walk test; BMI, body mass index; CF, cystic fibrosis; COPD, chronic obstructive pulmonary disease; ECMO/MV, extracorporeal membrane oxygenation/mechanical ventilation; $\mathrm{FEV}_{1}$, forced expiratory volume in 1 second; ICU, intensive care unit; ILD, interstitial lung disease.

In contrast, recipients with COPD receiving organs from donors 55 years or older had no significant differences in 90-day survival, 1-year survival or overall survival $(P=0.399)$ compared to those receiving organs from younger donors (Table 2 and Figure 4). When adjusting for other covariates, there was no significant association between donor age of 55 years or older and recipient survival in any of the 2 models (Table 3 ).

Recipients with ILD receiving organs from donors 55 years or older had significantly inferior 90-day survival, 1 -year survival, and overall survival $(P=0.038)$ compared with those receiving organs from younger donors (Table 2 and Figure 4). However, when adjusting for other covariates, the association between donors aged 55 years or older and survival was no longer significant in any of the 2 models (Table 3 ).

Finally, recipients in the "other" diagnoses group receiving organs from donors 55 years or older had no significant differences in 90-day survival, 1-year survival, or overall survival compared with those receiving organs from younger donors $(P=0.363)$ (Table 2 and Figure 4$)$. When adjusting for other covariates, there was no significant association between donor aged 55 years or older and survival (Table 3 ).

\section{DISCUSSION}

This multicenter study adds important insights to our understanding of the outcomes of LTx from older donors. Although donor age did not appear to be associated with overall recipient survival in the entire cohort, the association between donor age and survival differed significantly by recipient diagnosis. Specifically, the use of organs from donors 55 years or older was associated with inferior survival in recipients with CF. Also, recipients with CF receiving organs from donors 55 years or older had longer ICU LOS. In univariate analyses, recipients with ILD also had inferior survival when receiving organs from donors 55 years or older, but this association was not present when adjusting for recipient age and other covariates. Notably, there was a strong correlation between donor and recipient age in patients with ILD, and thus it is possible that the increased mortality seen in the group receiving older organs is due to recipient age and not donor age. Similarly, it is possible that the longer ICU LOS in this group reflects a higher risk of short-term complications associated with recipient age. To investigate this further, a larger ILD study population would be required. There were no significant differences in mortality or ICU LOS between patients receiving organs

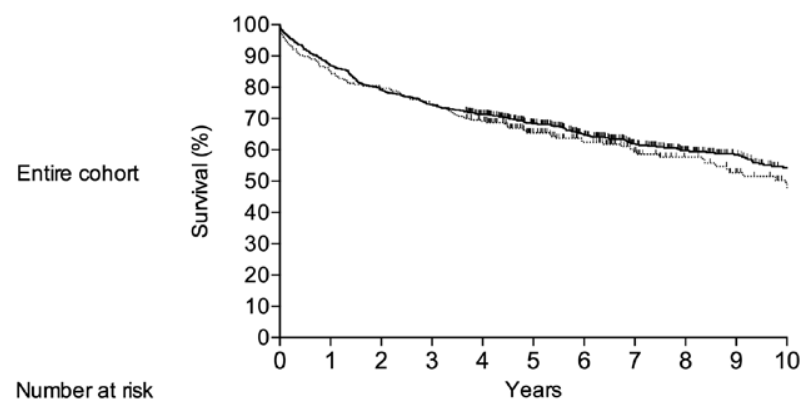

Number at nisk

\begin{tabular}{lllllllllllll}
\hline$\ldots$ & Donor Age $\geq 55$ & 256 & 218 & 204 & 191 & 170 & 126 & 99 & 75 & 59 & 47 & 36 \\
\hline- & Donor Age $<55$ & 657 & 572 & 521 & 490 & 450 & 380 & 311 & 247 & 197 & 162 & 131
\end{tabular}

FIGURE 3. Recipient survival after primary BLTx (excluding ReTx) stratified by donor age above or below the ideal donor criteria. BLTx, bilateral lung transplantation; ReTx, retransplantation. 


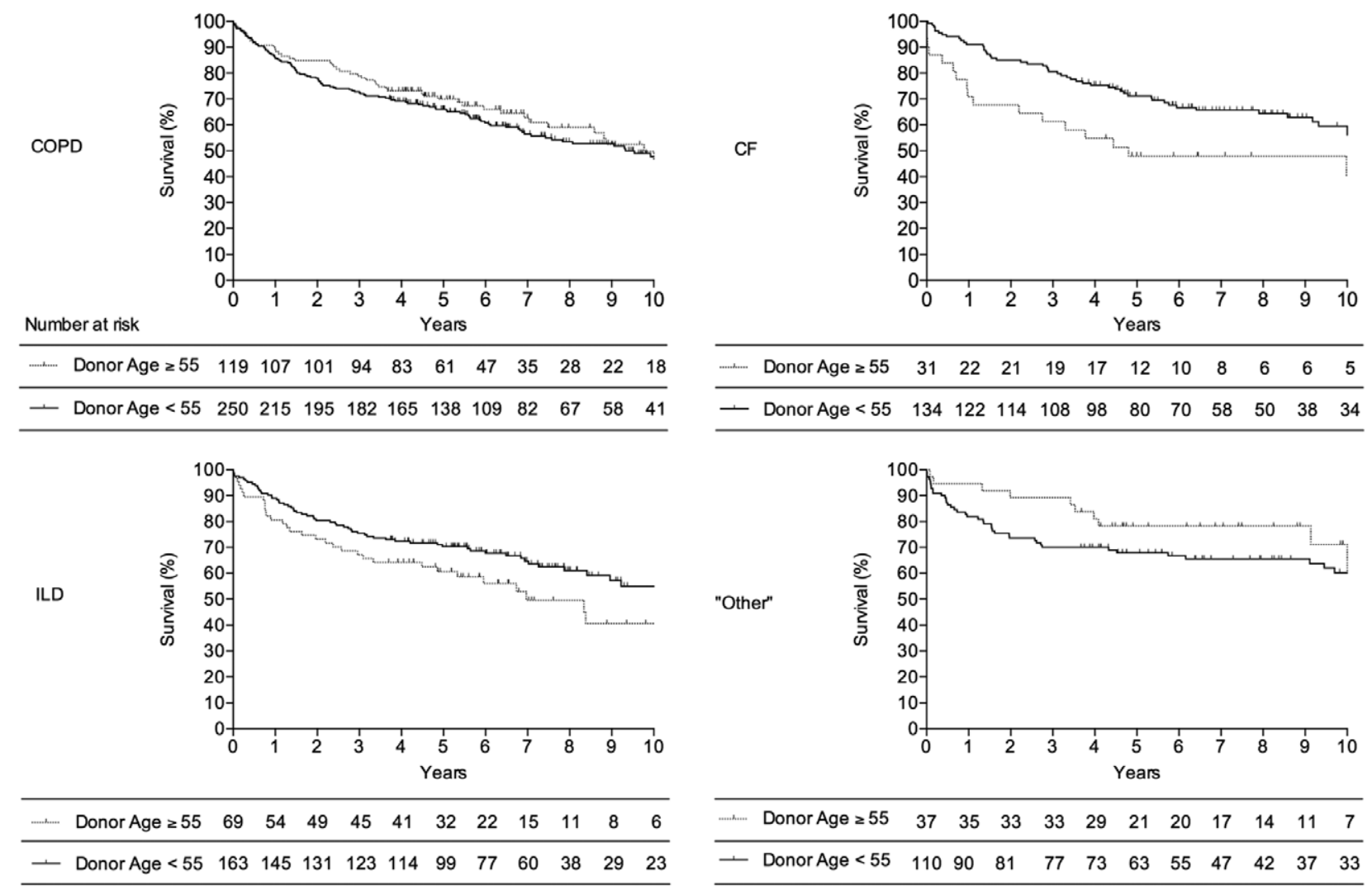

FIGURE 4. Recipient survival after primary BLTx (excluding ReTx) stratified by donor age above or below the ideal donor criteria for recipients with CF, COPD, ILD, and other diagnoses. BLTx, bilateral lung transplantation; CF, cystic fibrosis; COPD, chronic obstructive pulmonary disease; ILD, interstitial lung disease; ReTx, retransplantation.

from donors 55 years or older and those receiving organs from younger donors in the COPD and "other" group. Notably, the 3 most prevalent diagnoses in the "other" group were pulmonary hypertension, bronchiectasis, and LAM. However, a larger study population is required to analyze these groups individually.

\section{TABLE 3.}

\section{Multivariate models}

\begin{tabular}{|c|c|c|c|c|c|c|c|c|}
\hline & \multicolumn{2}{|c|}{$\mathrm{CF}$} & \multicolumn{2}{|c|}{ COPD } & \multicolumn{2}{|c|}{ ILD } & \multicolumn{2}{|c|}{ "Other" } \\
\hline & HR $(95 \% \mathrm{Cl})$ & $P$ & HR (95\% Cl) & $\boldsymbol{P}$ & HR (95\% Cl) & $P$ & HR $(95 \% \mathrm{Cl})$ & $P$ \\
\hline \multicolumn{9}{|l|}{$\begin{array}{l}\text { Excluding donor smoking } \\
\text { status }\end{array}$} \\
\hline Donor age $\geq 55$ y & $4.0(1.7-9.2)$ & $0.001^{*}$ & $0.8(0.5-1.2)$ & 0.332 & $1.3(0.7-2.5)$ & 0.348 & $0.5(0.2-1.3)$ & 0.160 \\
\hline Donor cause of death ${ }^{a}$ & $1.1(0.5-2.2)$ & 0.790 & $1.0(0.7-1.4)$ & 0.939 & $1.5(0.8-2.8)$ & 0.231 & $2.8(1.1-7.1)$ & $0.027^{\star}$ \\
\hline $\operatorname{Rec} \operatorname{age}^{b}, y$ & $1.7(1.2-2.6)$ & $0.008^{*}$ & $1.5(1.1-2.1)$ & $0.009^{*}$ & $1.0(0.8-1.3)$ & 0.884 & $1.5(1.1-2.0)$ & $0.024^{*}$ \\
\hline $\operatorname{Rec} B M I, k g / m^{2}$ & $0.9(0.7-1.0)$ & 0.086 & $1.0(0.9-1.1)$ & 0.878 & $1.0(0.9-1.1)$ & 0.442 & $1.0(0.9-1.1)$ & 0.638 \\
\hline Ischemia>330 min & $2.7(1.3-5.6)$ & $0.009^{*}$ & $1.1(0.7-1.8)$ & 0.563 & $1.2(0.7-2.0)$ & 0.554 & $0.8(0.3-1.8)$ & 0.573 \\
\hline $\begin{array}{l}\text { LS/urgent status }^{c} \\
\text { Including donor smoking } \\
\text { status }\end{array}$ & $0.6(0.2-1.6)$ & 0.325 & $1.0(0.3-2.7)$ & 0.924 & $0.7(0.3-1.6)$ & 0.388 & $0.7(0.2-3.0)$ & 0.618 \\
\hline Donor age $\geq 55$ y & $5.0(1.8-14.1)$ & $0.002^{*}$ & $0.9(0.6-1.5)$ & 0.760 & $0.7(0.3-1.9)$ & 0.520 & $0.7(0.2-2.0)$ & 0.479 \\
\hline Donor cause of death ${ }^{a}$ & $1.1(0.5-2.6)$ & 0.772 & $1.0(0.6-1.6)$ & 0.908 & $1.8(0.8-4.3)$ & 0.184 & $2.4(0.7-7.6)$ & 0.147 \\
\hline Donor smoking & $3.6(1.4-9.0)$ & $0.006^{*}$ & $0.7(0.5-1.2)$ & 0.186 & $1.4(0.7-2.7)$ & 0.366 & $1.5(0.6-3.8)$ & 0.418 \\
\hline $\operatorname{Rec} \operatorname{age}^{b}$ & $1.6(1.0-2.6)$ & $0.034^{*}$ & $1.4(1.0-2.1)$ & 0.066 & $1.2(0.8-1.8)$ & 0.320 & $1.2(0.8-1.8)$ & 0.302 \\
\hline $\operatorname{Rec} B M I, k g / m^{2}$ & $0.8(0.7-1.0)$ & 0.096 & $1.0(0.9-1.1)$ & 0.585 & $1.0(0.9-1.1)$ & 0.967 & $1.0(0.9-1.1)$ & 0.926 \\
\hline Ischemia >330 min & $4.1(1.5-11.4)$ & $0.006^{*}$ & $1.3(0.7-2.4)$ & 0.335 & $1.4(0.6-3.1)$ & 0.466 & $0.9(0.3-2.7)$ & 0.879 \\
\hline LS/urgent status ${ }^{c}$ & $1.0(0.3-3.3)$ & 0.936 & $0.5(0.1-3.5)$ & 0.450 & $0.7(0.2-3.3)$ & 0.661 & $0.3(0.1-2.3)$ & 0.237 \\
\hline
\end{tabular}

Cox regression models including covariates as described in methods.

${ }^{a}$ Donor cause of death shows stroke vs all other diagnoses.

${ }^{b}$ Hazard ratio given for every $10-y$ increase in recipient age.

${ }^{C}$ Recipient on pre-Tx life support or given urgent status in the Scandiatransplant Urgent Lung Allocation System.

$\mathrm{BMI}$, body mass index; CF, cystic fibrosis; Cl, confidence interval; COPD, chronic obstructive pulmonary disease; HR, hazard ratio; ILD, interstitial lung disease. 
Even though there are no official protocols for age matching or reserving organs from extended or older donors for older patients in our centers, we found a significant correlation between donor and recipient age among the COPD, ILD, and "other" groups. This could reflect a sentiment among transplant physicians that organs from older donors should be allocated to older recipients. It is also possible that older donors more frequently have other reasons to be considered "extended" and thus not offered to younger patients. Notably, however, there was no correlation between donor and recipient age in the CF group. It is conceivable that this may be because the CF population is generally younger, and that it is difficult to allocate age-matched organs to these patients, especially if urgency increases. Supporting this hypothesis, we did find that there was a significantly higher proportion of CF patients that was on ECMO or MV as bridge to TX, or listed as urgent in the Scandiatransplant International Organ Exchange System. Surprisingly, however, ECMO or MV was not associated with inferior survival among patients with CF. Thus, it is not likely that urgent status of the recipient may alone explain the reduced survival seen in CF patients who receive organs from a donor older than 55 years in our study.

Several studies about donor age and recipient outcome have been published previously with conflicting results. Some studies have demonstrated similar survival in recipients receiving organs from donors 50 years or older or donors 55 years or older compared with recipients receiving organs from younger donors. ${ }^{3-5,12}$ In 2013 , Bittle et al ${ }^{13}$ reviewed 10666 recipients in the UNOS registry from 2000 to 2010 and found similar survival in recipients receiving organs from donors aged 55 to 64 years, but inferior survival when using donors older than 65 years. However, a later study by Sommer et $\mathrm{al}^{14}$ demonstrated no difference in recipient survival when using donors $>70$ years. On the other hand, a recent study including 11835 recipients in the UNOS registry from 2005 to 2013 found significantly inferior survival in recipients receiving organs from donors older than 50 years compared with recipients receiving organs from younger donors. ${ }^{15}$ Finally, other studies have found that older donors yield inferior outcome in younger recipients or in recipients with pulmonary hypertension or prolonged cardiopulmonary bypass time. ${ }^{6,7}$

Our findings are in line with those studies demonstrating similar survival in recipient populations including all diagnoses when comparing the utilization of donors 55 years or older to younger donors. We could not find other studies examining the consequence of using older donors in specific recipient diagnosis groups. Notably, recipients with CF receiving older organs are often largely underrepresented in such studies, probably because of the general tendency to allocate older organs to older recipients.

The reason why older donors yield inferior results in recipients with CF and not other diagnoses is not obvious. It is plausible that donor-recipient age-mismatch plays a larger role in recipients with $\mathrm{CF}$ as they generally are younger and have fewer comorbidities, so survival to a higher degree is determined by the vitality of the lung graft and not other causes of death. Another explanation could be that old lungs have increased susceptibility for the bacterial colonization of the upper airways seen in recipients with $\mathrm{CF} .{ }^{16}$ Unfortunately, the data available to this study do not give further clues as to why CF patients seem to be the only group where donor age affects posttransplant survival.

This study has several limitations. First, it is a retrospective study with potential unmeasured confounders. In particular, it is difficult to quantify recipient urgency, and it is plausible that our analysis did not capture all aspects of urgency with the surrogate variables that were available. Second, data were not available for relevant end-points such as primary graft dysfunction, time on ventilator, acute rejection, and spirometry measurements. Also, although ICU LOS was available, the availability of various forms of step-down units and other local traditions may make the ICU LOS an end-point that is hard to generalize. However, we believe it is still a valid end-point in this study, as it does indicate significant differences in the early posttransplant status among the groups compared in this multicenter study. Furthermore, some variables had missing data, and some subjects were therefore excluded from the analyses. Third, generalizability could be limited as relatively few recipients were older than 65 years, and few were on life support with MV or ECMO at the time of transplant. Finally, whether a donor age of 55 years is the optimal cutoff value for recipients with CF was not tested in this study and needs to be explored in studies with larger study populations. The main strengths of this study are the multicenter design and relatively high number of included recipients with CF receiving lungs from older donors.

In conclusion, our results indicate that the ideal donor age criterion of 55 years should be taken into account when considering a potential donor for a patient with CF. However, the risk of using an older donor must be carefully weighed against the risk of remaining on the waiting list. Furthermore, our findings should be confirmed in other studies with larger datasets. For recipients with other diagnoses, our findings support that lungs from donors aged 55 years or older can be safely used for LTx.

\section{ACKNOWLEDGMENTS}

The authors thank Ilse Duus Weinreich for her valuable help with the Scandiatransplant registry.

\section{REFERENCES}

1. Report of the Madrid consultation: part 1: European and universal challenges in organ donation and transplantation, searching for global solutions. Transplantation. 2011;91:S39-S66.

2. Orens JB, Boehler A, de Perrot M, et al. A review of lung transplant donor acceptability criteria. J Heart Lung Transplant. 2003;22:1183-1200.

3. Bhorade SM, Vigneswaran W, McCabe MA, et al. Liberalization of donor criteria may expand the donor pool without adverse consequence in lung transplantation. J Heart Lung Transplant. 2000;19:1199-1204.

4. Fischer S, Gohrbandt B, Struckmeier P, et al. Lung transplantation with lungs from donors fifty years of age and older. J Thorac Cardiovasc Surg. 2005;129:919-925.

5. Dahlman S, Jeppsson A, Scherstén $H$, et al. Expanding the donor pool: lung transplantation with donors 55 years and older. Transplant Proc. 2006;38:2691-2693

6. Hayes D Jr, Black SM, Tobias JD, et al. Influence of donor and recipient age in lung transplantation. J Heart Lung Transplant. 2015;34:43-49.

7. Shigemura N, Horai T, Bhama JK, et al. Lung transplantation with lungs from older donors: recipient and surgical factors affect outcomes. Transplantation. 2014;98:903-908.

8. Quanjer PH, Tammeling GJ, Cotes JE, et al. Lung volumes and forced ventilatory flows. Eur Respir J. 1993;6(Suppl 16):5-40. 
9. Guidelines for organ exchange in the Scandiatransplant area. Available at http://www.scandiatransplant.org/members/nttr/Guideline_SHLG_ oct_2017.pdf.

10. Textor J, Hardt J, Knüppel S. DAGitty: a graphical tool for analyzing causal diagrams. Epidemiology. 2011;22:745.

11. Thabut G, Mal H, Cerrina J, et al. Graft ischemic time and outcome of lung transplantation: a multicenter analysis. Am J Respir Crit Care Med. 2005;171:786-791.

12. Pizanis N, Heckmann J, Tsagakis K, et al. Lung transplantation using donors 55 years and older: is it safe or just a way out of organ shortage? Eur J Cardiothorac Surg. 2010;38:192-197.
13. Bittle GJ, Sanchez PG, Kon ZN, et al. The use of lung donors older than 55 years: a review of the united network of organ sharing database. J Heart Lung Transplant. 2013;32:760-768.

14. Sommer W, lus F, Salman J, et al. Survival and spirometry outcomes after lung transplantation from donors aged 70 years and older. $J$ Heart Lung Transplant. 2015;34:1325-1333.

15. Mulvihill MS, Gulack BC, Ganapathi AM, et al. The association of donor age and survival is independent of ischemic time following deceased donor lung transplantation. Clin Transplant. 2017;31:e12993.

16. Gyetko MR, Toews GB. Immunology of the aging lung. Clin Chest Med. 1993;14:379-391. 